\title{
INFLUENCE OF VELOCITY MOMENTS ON SAND BAR MOVEMENT DURING CROSSTEX
}

\author{
Gregory Guannel $^{1}$, H. Tuba Özkan-Haller ${ }^{2}$, Merrick C. Haller ${ }^{1}$, James T. Kirby ${ }^{3}$
}

1. Department of Civil, Constr., and Env. Engineering, Oregon State University, Corvallis, OR 97331 USA; guannelg@engr.orst.edu, hallerm@engr.orst.edu.

2. College of Oceanic and Atmospheric Sciences, Oregon State University, Corvallis OR 97331 USA; ozkan@coas.oregonstate.edu.

3. Center for Applied Coastal Research, University of Delaware, Newark, DE 19716 USA; kirby@udel.edu.

\begin{abstract}
During the 2005 CROSSTEX laboratory experiments, a series of bar generation and degeneration events and repeated cycles of offshore and onshore transport were documented. These changes were driven by regular modifications to the specified incident wave field. Based on collected bathymetric data we first assessed the spatial and temporal movement of two sand bars. We used hydrodynamic and video data to relate the movement of these bars to the occurrence of wave breaking and the magnitudes of undertow, velocity skewness and acceleration skewness. This analysis indicates that undertow currents generated the first sand bar through offshore-directed transport. The second bar was formed by onshore transport, with the first bar serving as the likely sediment source. On the other hand, onshore migration and degeneration of both sand bars correlated well with acceleration skewness.
\end{abstract}

\section{INTRODUCTION}

Many investigations in the recent past have focused on identifying processes responsible for cross-shore sediment movement and sand bar migration in the surf. It is now widely accepted that undertow currents move sediment offshore (Thornton and Humiston, 1996; Gallagher et al., 1998; Elgar et al., 2001) and are responsible for the formation of sand bars. On the other hand, processes responsible for onshore sediment movement are more difficult to pinpoint, although recent efforts indicate that acceleration skewness and other factors, such as drift velocity, boundary layer 
streaming, pressure gradients, or plug flow might play significant roles (e.g. Hoefel and Elgar, 2003; Henderson et al., 2004, Foster et al., 2006).

Experimental data is required in order to evaluate the relative importance of the various transport processes. However, while there is currently a wealth of data involving offshore bar migration events, there is relatively little concerning onshore migration. To fill that gap, the CROSSTEX (CROss-Shore Sediment Transport EXperiment) experiment was conducted at the O. H. Hinsdale Wave Research Laboratory (HWRL) at Oregon State University.

Four different teams of investigators were involved in CROSSTEX, each focusing on different processes, such as the evolution of sand ripples, turbulence, sand bar migration and swash zone processes. The present authors were principally involved in the sand bar migration portion of these experiments, which will be discussed in further detail in the remainder of this paper.

In the following sections, we will first describe the set-up and implementation of the experiment. Then we will describe the spatial and temporal evolution of the bars, and relate the evolution to the measured velocity moments. Finally, we will investigate correlations between the spatial and temporal evolutions of two of these bars with variables such as wave breaking, the undertow strength, velocity skewness, and acceleration skewness.

\section{EXPERIMENTS AND BED RESPONSE}

\section{Experimental set-up}

CROSSTEX took place in the HWRL's 104m-long Large Wave Flume (LWF; see Figure 1) from June to September 2005. This flume was selected because its dimensions are ideal to conduct most experiments at near prototype scale. For these experiments the LWF was filled with well sorted, fine to medium sand mined from Florence, Oregon, with a median grain size $\mathrm{D}_{50}=0.22 \mathrm{~mm}$, and a standard deviation of $\sigma_{\Phi}=0.3$. Prior to our experiments, the bed profile was adjusted to an average slope of $1 \mathrm{~V}: 20 \mathrm{H}$ through wave action.

The LWF is equipped with a flap wavemaker that can generate regular and irregular waves, a mobile cart with a vertically moving frame where various instruments can be mounted, as well as a Multiple Transducer Array (MTA) to conduct bathymetric surveys. The coordinate origin is located on top of the east wall of the tank and aligned with the wave paddle. Consequently, in all tables and figures presented in this paper, $\mathrm{X}$ is onshore positive and $\mathrm{Z}$ is positive up. 


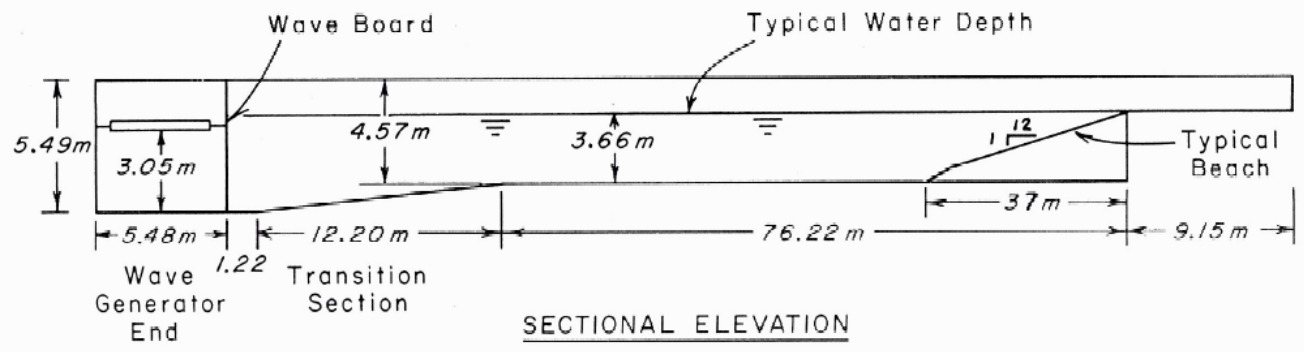

Figure 1: Typical cross-section of the Large Wave Flume

The cross-shore evolution of water surface elevation was measured with twelve resistance-type wave gauges mounted along the walls of the flume. Eight wallmounted Vectrino Acoustic Doppler Velocimeters (ADVs) and Optical Backscatter Sensors (OBSs) were also deployed in order to observe the near-bottom hydrodynamics and sediment concentrations, as depicted in Figure 2 and in Table 1.

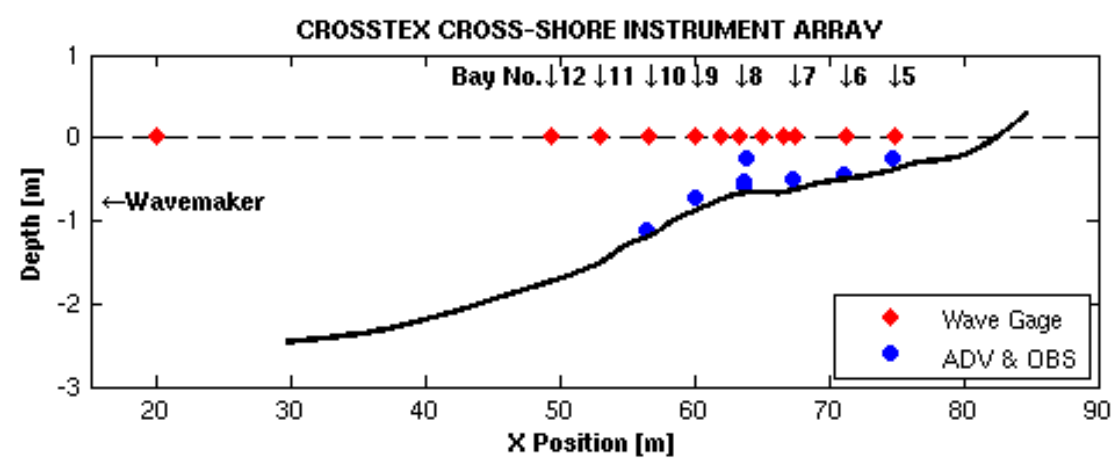

Figure 2: Instruments along wave flume. Circles show position of ADVs and OBSs, and diamonds show position of wave gages.

Table 1: Position of Wall Mounted ADVs and OBSs

\begin{tabular}{|c|c|c|c|c|c|c|c|c|c|}
\hline \multicolumn{2}{|c|}{ Bay } & 5 & 6 & 7 & \multicolumn{3}{|c|}{8} & 9 & 10 \\
\hline \multirow{2}{*}{$\mathbf{X}[\mathrm{m}]$} & ADV & 75 & 71 & 67 & 64 & 64 & 64 & 60 & 56 \\
\cline { 2 - 12 } & OBS & 75 & 71 & 67 & 64 & 64 & 64 & 60 & 56 \\
\hline \multicolumn{2}{|l}{ Dist. Abv Bed [cm] } & 10 & 2 & 7 & 9 & 5 & 42 & 9 & 4 \\
\hline
\end{tabular}

In addition to wall-mounted instruments, one wave gauge, eight ADVs, four Electromagnetic Current Meters (EMCMs), seven OBS, and twenty Fiber-Optic Backscatter Sensors (FOBSs) were also placed on the cart's mobile frame. Typical elevations of the cart instruments during deployments are presented in Figure 3.

Cart instruments were deployed at different cross-shore locations during different runs, and lowered before each wave run so that the lowermost ADVs would capture velocity fluctuations at one centimeter above the bed, and the lowermost FOBS sensor would sit one centimeter inside the fixed bed. Finally, three ARGUS cameras (Holman, et al., 1993) were installed above the LWF and are used here to evaluate percent wave breaking at various cross-shore locations. 


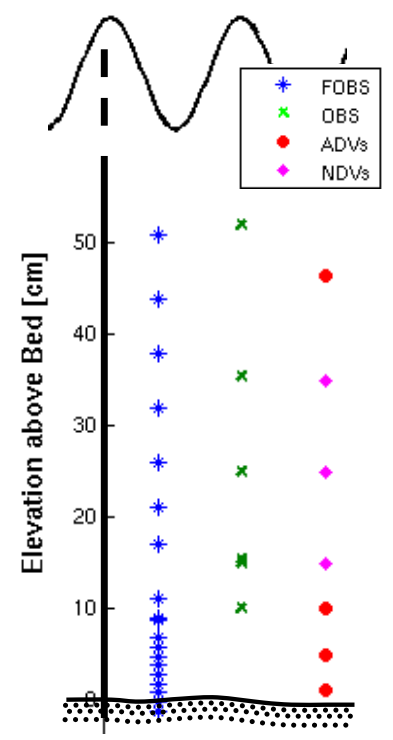

Figure 3: Typical arrangement and elevation of cart mounted instruments.

\section{Experimental conditions}

The objectives of the experiment were to first generate an offshore breaker bar and then to move that bar onshore. Consequently, the generated wave field (TMA spectrum) was modified as the experiment progressed. At the beginning, relatively high energy waves were generated to move sediment offshore. Once an offshore bar was generated, wave height and period were adjusted to create conditions conducive to onshore bar movement (see Table 2). Regular bathymetric surveys were performed to verify that designed waves were indeed causing the bar(s) to move in the intended direction.

Table 2: Consecutive Wave Conditions during Experiment

\begin{tabular}{|c|c|c|}
\hline $\begin{array}{c}\text { Wave Height } \\
{[\mathrm{m}]}\end{array}$ & $\begin{array}{c}\text { Wave Period } \\
{[\mathbf{s}]}\end{array}$ & $\begin{array}{c}\text { Wave Time } \\
{[\mathrm{min}]}\end{array}$ \\
\hline 0.60 & 4.0 & 210 \\
\hline $0.30-0.32$ & 8.0 & 675 \\
\hline $0.55-0.35$ & 3.5 & 135 \\
\hline $0.40-0.32$ & 5.5 & 330 \\
\hline $0.320-0.175$ & 3.5 & 795 \\
\hline
\end{tabular}

The experiment involved approximately 36.5 hours of wave action ( 36.5 wave hours), and consisted of several fifteen minutes runs (or 15 wave minutes). This length was determined based the limitations of the data acquisition system, and to limit effects of seiching.

\section{Bed evolution}

Three main stages of bed evolution were identified during the course of the experiment: 
1. Generation of an offshore bar (Figure 4a), during the first 210 minutes of waves.

2. Recession of the offshore bar and growth of a "middle bar" (Figure 4b), from wave time 210 to 900 minutes.

3. Recession of middle bar and smoothing of profile (Figure 4c), from wave time 900 to 2200 minutes.

It is worth mentioning that we also observed the rapid formation and decay of a nearshore terrace/bar very close to shore, while the middle bar was still evolving. Also, we observed the formation of mega-ripples (Figure 4b, final profile) between the middle bar and the nearshore terrace, or bar. We will not evaluate the dynamics of these bedforms in this paper.
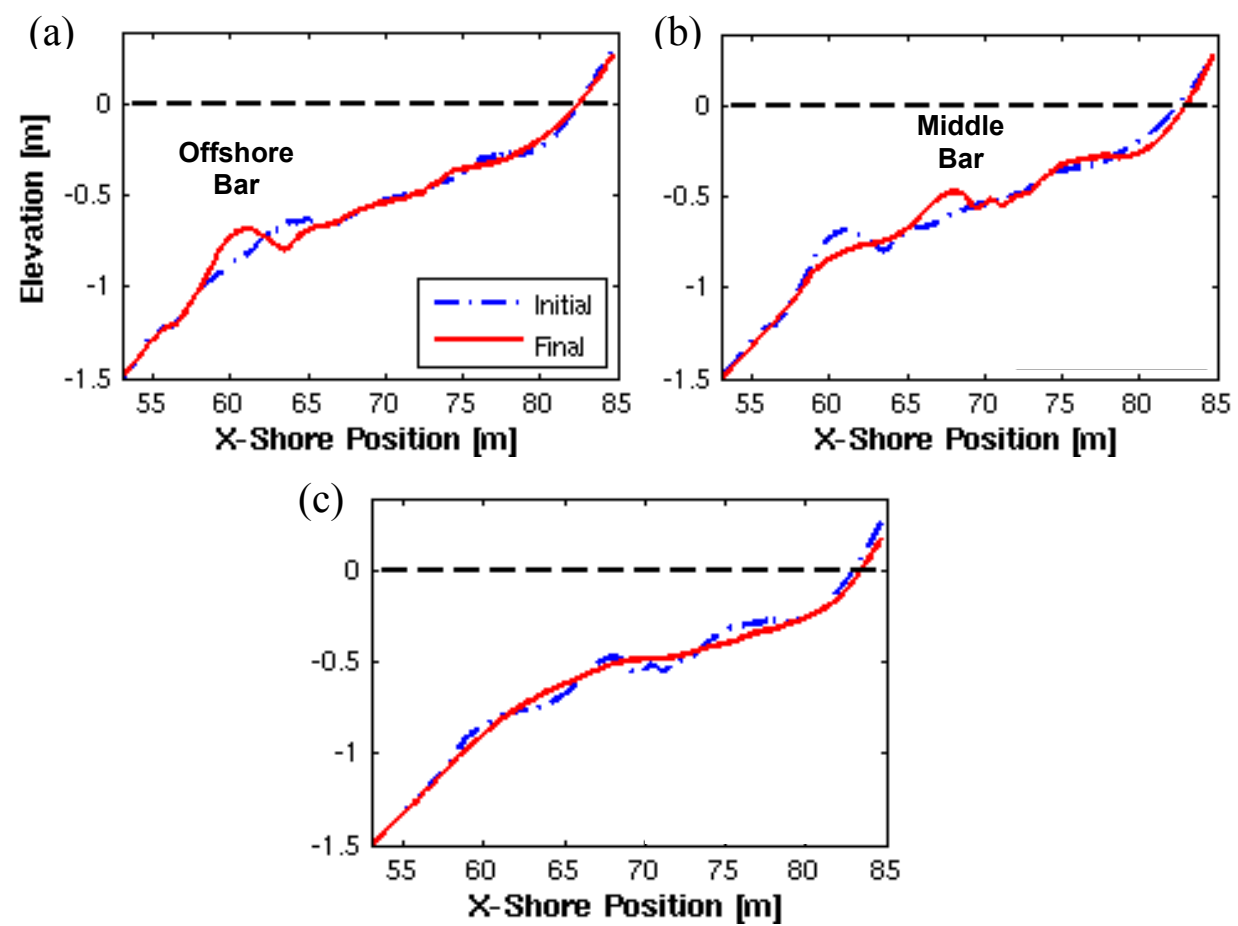

Figure 4: Bed Profile Evolution during CROSSTEX Experiment. Initial and final bathymetries are shown by the dashed and solid lines, respectively.

In conclusion, during this experiment we were able to generate three sand bars and other bedforms by varying wave conditions in the tank. Furthermore, we collected detailed bathymetric, hydrodynamic and sediment concentration data at various locations throughout the tests. These data will enable us to better evaluate wave conditions and processes responsible for cross-shore sediment movement. In the remainder of this paper, we will focus on the life cycle of the offshore and middle bars.

\section{WAVE CONDITIONS AND SAND BAR GENERATION/DEGENERATION}

In order to characterize the morphologic response to the range of wave fields generated in the LWF, we identified several representative parameters for the offshore and middle sand bars, as defined in Figure 5, and tracked their evolution 
through time. These parameters were bar height and position, and bar half-width. Together, these parameters provide a good, general representation of the spatial and temporal evolution of the two bars.

As mentioned earlier, undertow and acceleration skewness have been recognized as cross-shore velocity moments that correlate well with cross-shore migration of sand bars. So, in order to assess their role in the evolution of the sand bars, we will relate these quantities, as well as amount of breaking, to the temporal and spatial characteristics of the bars. Some of the hypotheses drawn from this analysis will be confirmed by looking at sediment flux values, which provide information about sediment sources and pathways.

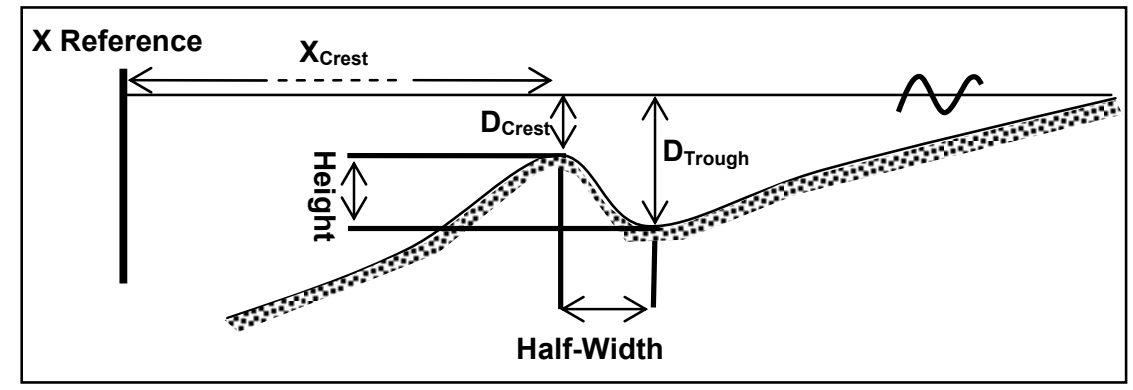

Figure 5: Definition of bar geometry

\section{Spatial and Temporal Evolution of Sand Bars}

Using the computed bathymetric data, we first plotted bar height versus cross-shore position for the two bars (Figure 6). These figures show that the bars take different paths during generation when their heights start to increase and during degeneration, when height decreases; initial and final position during this cycle are close, but not identical.
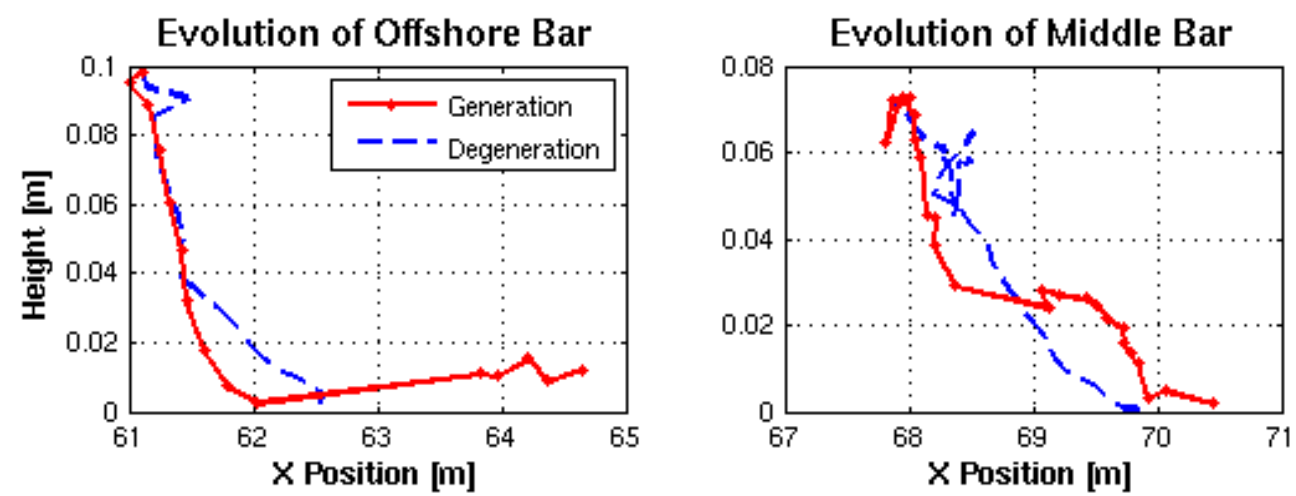

Figure 6: Bar height versus cross-shore position for the offshore and middle bars.

We also plotted bar height and position as a function of time for both sand bars, as shown in the third and fourth panels of Figure 7. In this figure, we also show percent of wave breaking (color bars, second panel) computed from the Argus videos that were collected during 23 runs. We do not have data for the other runs, so most of the color bars are separated by white space. 


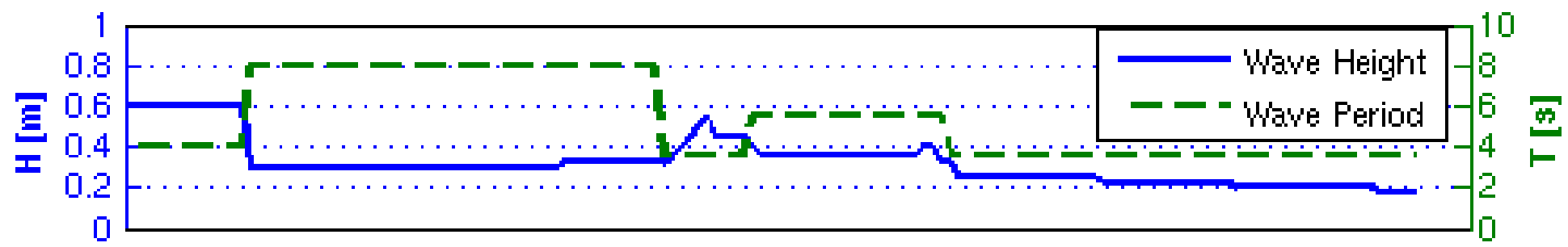

Percent Breaking
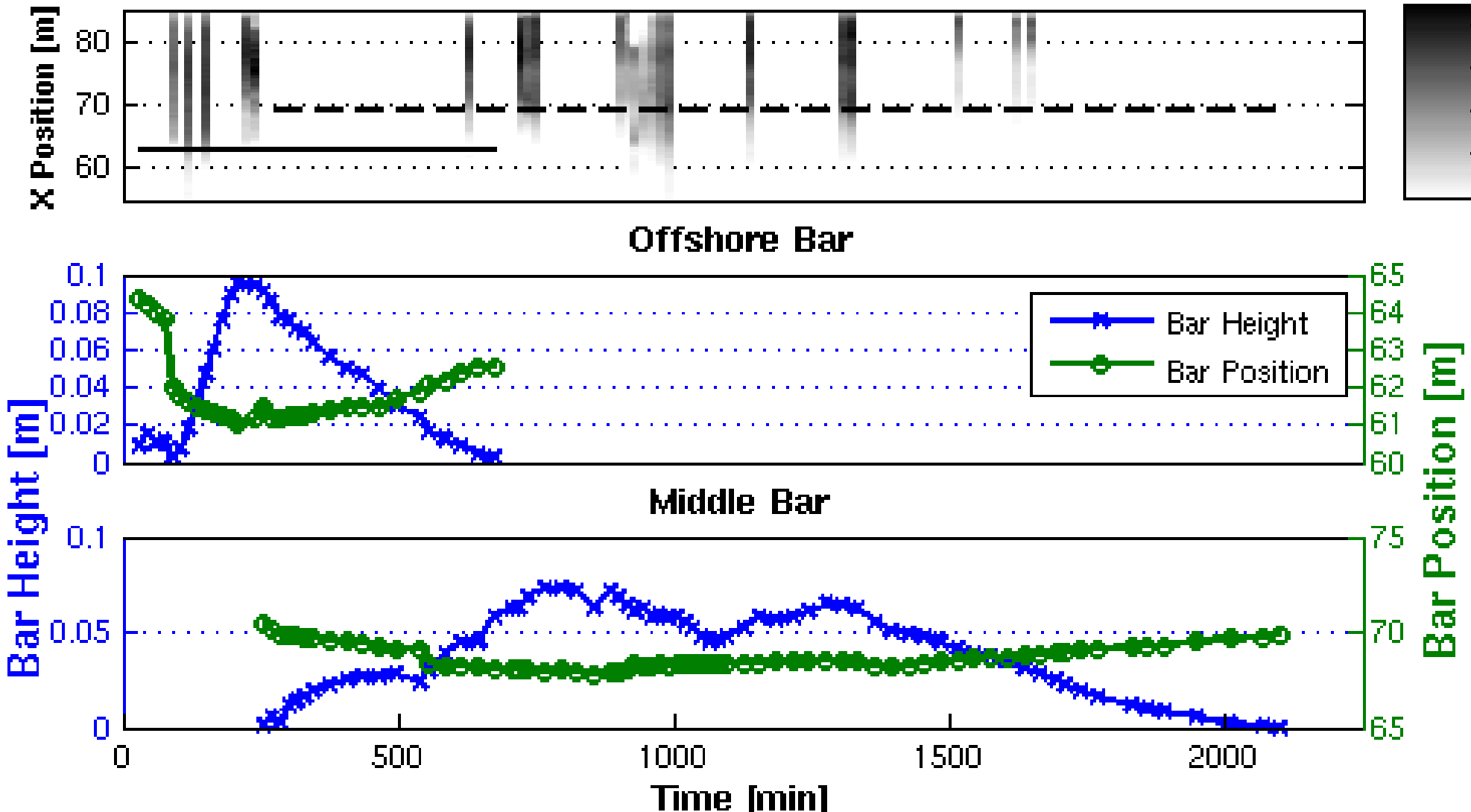

Figure 7: Spatial and Temporal evolution of the offshore and middle bars. Generated wave field is shown in top panel, and percent of wave breaking for 23 discrete runs by the color bars in $2^{\text {nd }}$ panel, where solid and dashed line show average position of the offshore and middle bars, respectively. Third and fourth panel show bar height (solid line with crosses) and position (solid line with circles). 
At the beginning of the experiment, under the attack of fairly high, energetic waves (Figure 7, top panel), sediment moved offshore and started to accumulate at approximately $\mathrm{x}=64 \mathrm{~m}$ to form an offshore bar (Figure 7, third panel). This bar continued to move offshore at a speed of approximately $1 \mathrm{~cm} / \mathrm{min}$ as it grew in height, until wave conditions changed at wave time $210 \mathrm{~min}$. During that period, approximately 40 percent of the waves were breaking on the offshore bar, and approximately 70 percent of the waves were breaking just shoreward of it (Figure 7, second panel).

Almost immediately after the change in wave field, offshore bar height started to decrease as the bar moved onshore at a speed of approximately $0.3 \mathrm{~cm} / \mathrm{min}$. Simultaneously, the middle bar started to form. Similarly to the offshore bar, its height increased as it moved offshore (Figure 7, third and fourth panels), but its speed was approximately $0.3 \mathrm{~cm} / \mathrm{min}$. The middle bar generation, which will be referred as Phase I in the remainder of this paper, continued until wave conditions were changed, at around wave time $900 \mathrm{~min}$. During this period, between 30 and 40 percent of the waves were breaking on top of the middle bar. In contrast, approximately less than five percent of the waves were breaking on top of the offshore bar, which continued to degenerate.

Successive changes in wave conditions, between wave time 900 and $1350 \mathrm{~min}$, resulted in changes in middle bar height (slight decrease during Phase II and slight increase during Phase III), while it continued to move very slowly onshore. Reduction in wave height and period at wave time $1350 \mathrm{~min}$ led to the final decay and onshore migration of the middle bar (Phase IV). During this phase, less than five percent of the waves were breaking on top of the bar, and the bar moved onshore at a speed of approximately $0.1 \mathrm{~cm} / \mathrm{min}$, which is smaller than the onshore migration speed of the offshore bar.

The information gathered from these figures along with bar half-width data (not shown), describe the bars temporal and spatial evolution. Both bars were generated when wave breaking was moderate above their crest, and as they moved offshore, they grew higher and wider. After changes in wave conditions, the bars decayed and moved onshore, while getting shorter and narrower, with almost no wave breaking on them. The two sand bars are very dynamic, responded quite rapidly to changes in the wave field, and are probably interdependent.

Moreover, we expect undertow currents to be associated with the principal mechanisms of bar formation, but play a weaker role in bar decay. Other processes, such as the ones correlated with acceleration skewness, are expected to become more predominant during bar degenration. The relationship between velocity moments and sand bars temporal and spatial evolution will be analyzed in more detail in the next section. 


\section{Influence of Velocity moments}

To compute values of undertow, acceleration skewness and velocity skewness, and to evaluate their influence on the evolution of the bars, we used records of wall instruments located immediately shoreward and offshore of the bars. These records have been band-passed to remove turbulence and seiching signals.

During offshore bar generation, Figure 8, undertow and velocity skewness values were relatively high shoreward of the bar, while acceleration skewness was relatively modest. Furthermore, while gradients of undertow and acceleration skewness seemed to be fairly strong on top of the bar, there was no significant change in velocity skewness in that region.

During offshore bar degeneration, overall undertow and velocity skewness values decreased, while acceleration skewness values shoreward of the bar increased. Again, gradients in undertow and acceleration skewness seemed to be strong near the bar, while velocity skewness did not vary much. Also, it is interesting to note that while acceleration skewness values were higher offshore of the bar during the generation phase, they became larger shoreward of the bar during the bar degeneration.
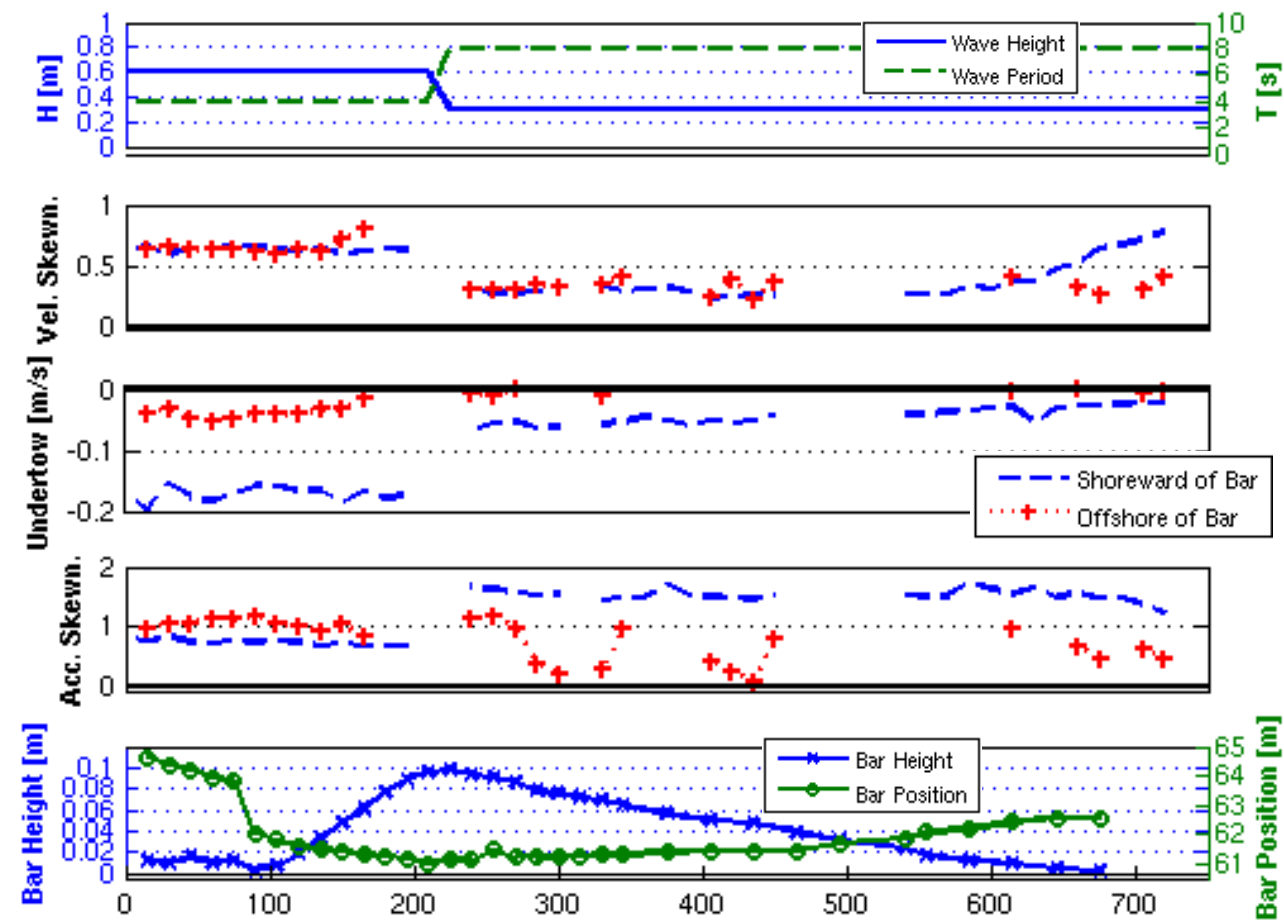

Time [min]

Figure 8: Velocity moments and offshore bar spatial evolution. Generated wave field is shown in top panel, velocity skewness, undertow and acceleration skewness shoreward (dashed lines) and offshore of the bar (dotted lines with crosses) in $2^{\text {nd }}, 3^{\text {rd }}, 4^{\text {th }}$ panels, and bar height (solid line with crosses) and position (solid line with circles) in bottom panel.

Another way to look at the influence of wave moments on the evolution of the offshore bar is presented in the left panel of Figure 9, where undertow values 
measured during generation and degeneration phases are plotted as a function of acceleration skewness. This figure, combined with the information presented in previous figures, show that the bar generated during strong undertow conditions, but degenerated in the presence of very weak undertow and strong accelerations skewness.
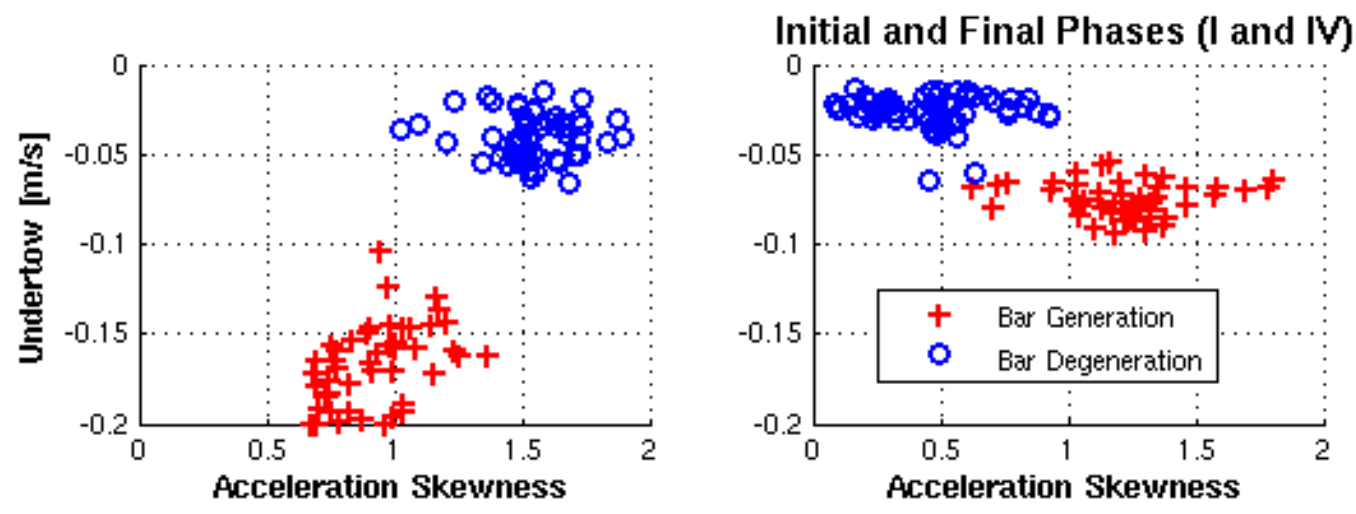

Figure 9: Undertow current versus acceleration skewness values during offshore (left panel) and middle (right panel) bar generation (crosses) and degeneration (circles).

A similar analysis was conducted for the middle bar, as shown in Figure 10. During middle bar initial generation, Phase I, values of velocity skewness offshore and shoreward of the bar decreased, compared to values it had from the beginning of the experiment to wave time $210 \mathrm{~min}$. On the other hand, gradients of that moment increased. Undertow strength shoreward of the bar remained stable, but it decreased from values it had before wave time $210 \mathrm{~min}$. Gradients of undertow decreased also during that period. Finally, acceleration skewness values on either side of the bar decreased during that period. The reduction of that moment was stronger offshore than shoreward of the bar.

During Phases II and III, strength of the undertow near the bar did not change much, velocity and acceleration skewness varied. However, as mentioned earlier, these are intermediate states in the evolution of the middle bar, and we will not evaluate influence of moments on Phases II and III any further.

During the bar final degeneration, Phase IV, velocity skewness values decreased, and undertow current is almost null, and both have almost zero gradient over the bar. On the other hand, acceleration skewness values decreased, although its gradient is still significant on top of the bar. 

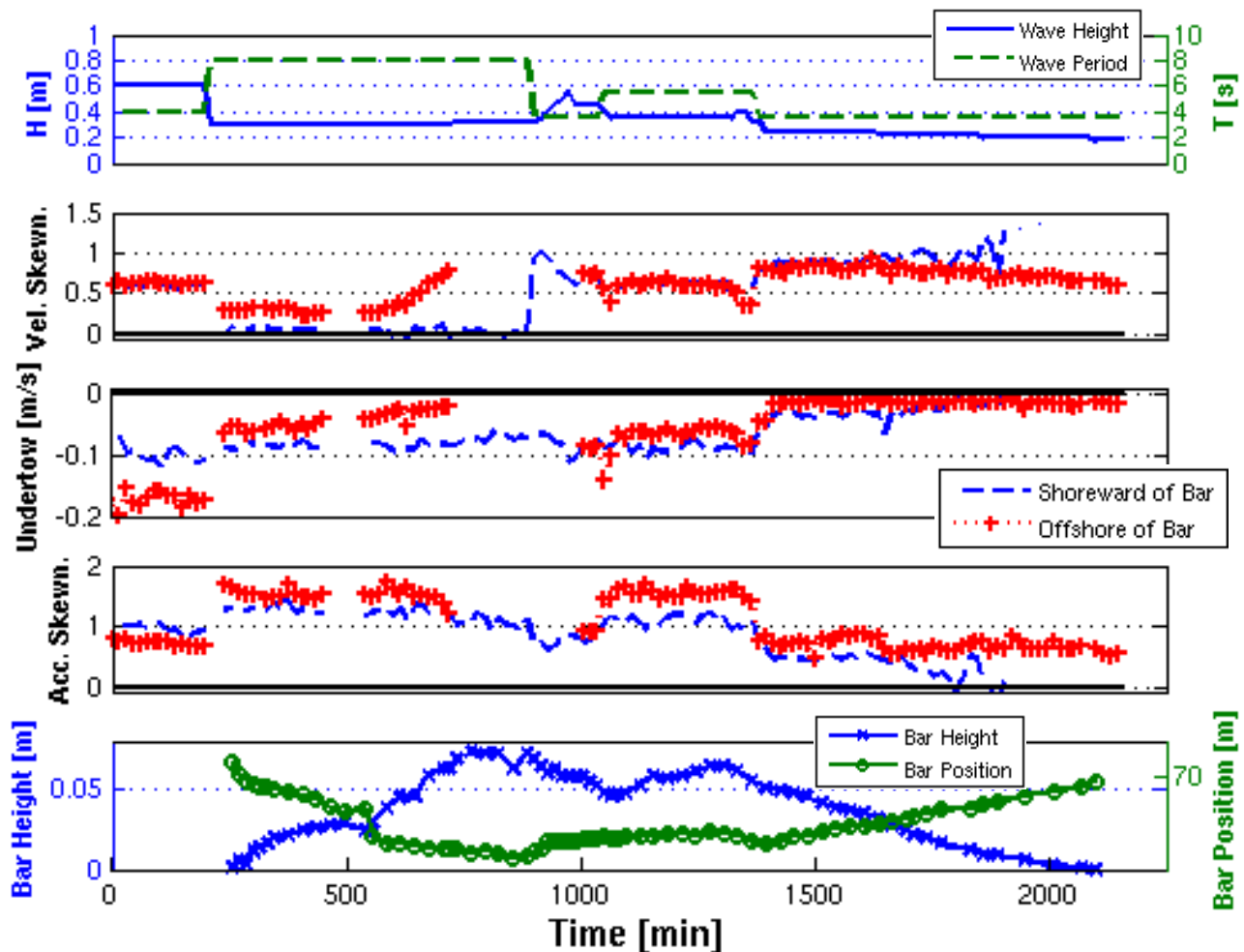

Figure 10: Velocity moments and middle bar spatial evolution. Generated wave field is shown in top panel, velocity skewness, undertow and acceleration skewness shoreward (dashed lines) and offshore of the bar (dotted lines with crosses) in $2^{\text {nd }}, 3^{\text {rd }}, 4^{\text {th }}$ panels, and bar height (solid line with crosses) and position (solid line with circles) in bottom panel.

When we combined information presented in the previous figure with the distribution of undertow versus acceleration skewness values (right panel of Figure 9), we see that the middle bar formed when undertow currents were approximately 50 percent lower than what they were during generation of the offshore bar. Also, acceleration skewness values during that period were 50 percent higher than what they were during generation of the offshore bar. This situation suggests that the middle bar was not undertow-formed, which is characteristic of most sand bars (such as the offshore bar). On the other hand, because gradients of acceleration skewness were moderate over the middle bar during that bedform degeneration, but undertow currents were almost non-existent, it is likely that processes related to this moment were responsible for the decay of that bar.

In summary, the information presented in these figures indicates that 1 . velocity skewness did not seem to be a major factor in the life cycle of either bedforms; 2 . undertow currents were probably responsible for the offshore bar growth, but might have been only been partially responsible for the formation of the middle bar. Other processes, probably correlated with acceleration skewness, might have been more prevalent.

It is likely that processes correlated with acceleration skewness led to the degeneration of both bars, but that the value of that moment played a role in the 
onshore migration speed of both bars: the offshore bar moved onshore quicker than the middle bar probably because acceleration skewness was higher in one case than the other. One way to assess some of these hypotheses is to compute sediment flux values $\mathrm{Q}$ and evaluate the origin of sediments that led to the generation of these bars.

\section{Sediment Flux Calculation}

Sediment fluxes that led to the generation of the offshore and middle bars (Figures 11) were computed from the integration of the difference between pre- and postsandbar generation bed profiles. In this figure, negative flux means offshore sediment transport, while negative flux signifies onshore movement.

Analysis of the left panel of Figure 11 shows that the offshore bar was mostly generated by the offshore movement of a fair amount of sediments, and to a lesser extent by sediment that moved from offshore regions. Most of the sediments that moved offshore seem to originate to regions less than five meters shoreward of the bar.

Based on results of previous sections, we can infer that most sediment that moved offshore was mobilized and moved by undertow currents. Offshore of the bar, because undertow currents were weak, wave processes (possibly acceleration skewness) became predominant and moved some sediment onshore. Sediments accumulated at the final bar location due to the confluence of erosive (i.e. undertow driven) and accretive (i.e. acceleration skewness driven) processes.

If we now look at the middle bar (Figure 11, right panel), it appears that most of the sediments that led to its formation moved onshore from the offshore bar that was degenerating. This movement of sediment, probably driven by acceleration skewness related processes, seemed to have continued beyond the location of the middle bar, but at a lower rate. The change in flux intensity near the trough of the middle bar suggests that onshore sediment movement shoreward of the bar was probably slowed by other processes, such as the undertow.
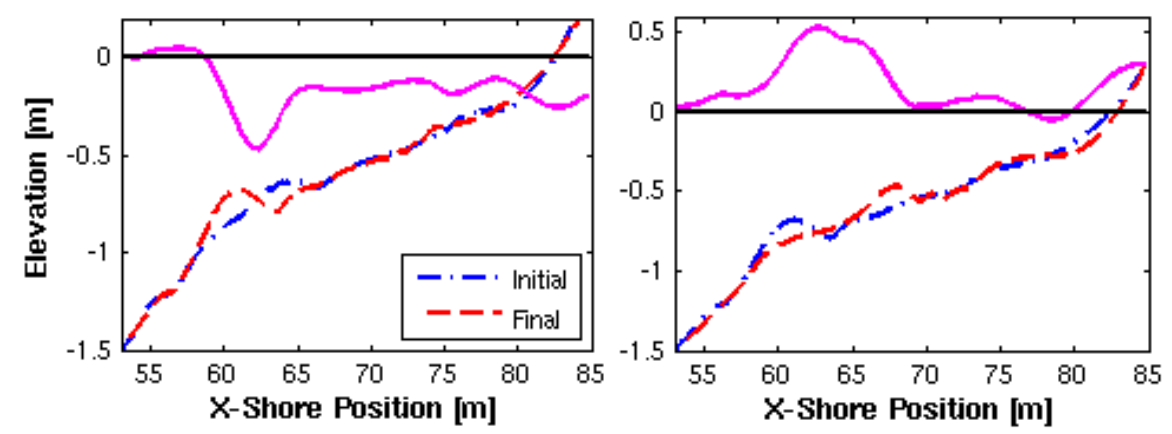

Figure 11: Sediment flux $Q$ (solid line) computed from the difference between initial (dashed dotted line) and final (dashed line) profiles during generation of offshore (left panel), and middle bars (right panel). Offshore sediment movement corresponds to a negative $Q$. 


\section{CONCLUSIONS}

During this portion of the CROSSTEX experiment, the generation and degeneration of an offshore and a middle bar was studied in a controlled environment. The analysis of the temporal and spatial evolution of these bars showed that they were quite responsive to changes in wave conditions, interdependent, and sensitive to velocity moments.

Our analysis indicates that the offshore bar was formed by the action of undertow currents, caused by intense wave breaking. On the other hand, the middle bar appears to have been formed by the onshore movement of sediments originating from the offshore bar. Undertow currents and acceleration skewness played a role in this movement, but their relative importance is different from what occurred during the life cycle of the offshore bar. Finally, the degeneration of these bars is correlated with weaker undertow currents, higher acceleration skewness, and almost nonexistent breaking. What separates them is their rate of decay, which is probably dictated by the value of acceleration skewness.

In conclusion, the two sand bars were probably formed by different processes, but were extremely interdependent. In a sense they might even represent the same bedform that evolved in different ways because of the ever changing balance between processes that drive cross-shore sediment movement. These processes are correlated with moments such as undertow and acceleration skewness, but their exact nature, and the way they mobilize sediment particles and move them has yet to be determined. This is especially true for acceleration skewness related processes. Further analysis of the data that was collected might shed a light on the role of that moment.

\section{ACKNOWLEDGEMENTS}

We wish to thank all the faculty and staff of the O.H. Hinsdale Wave Research Laboratory for their time and support during the experimental phase of CROSSTEX. The O.H. Hinsdale Wave Research Laboratory is partially supported by the George E. Brown Jr. Network for Earthquake Engineering Simulation (NEES) Consortium Incorporated contract OMSA v.3.1 through their National Science Foundation Cooperative Agreement CMS-0402490. Some of the instrumentation used in this project was purchased under National Science Foundation NSF-0429219. Also, we would like to thank Patricio Catalan for his help in computing percent of wave breaking from the Argus videos. Finally, we would like to thank our sponsors for this study, NSF Grant OCE-0351297 and OCE-0351153, and Sea Grant grant NA16RG1039.

\section{REFERENCES}

Elgar, S., E. Gallagher, and Guza, R. T. (2001). "Nearshore sand bar migration", Journal of Geophysical Research, 106(C6), 11,623-11,627.

Foster D. L., Bowen, A. J., Holman, R. A., Natoo, P. (2006). "Field evidence of 
pressure gradient induced incipient motion", Journal of Geophysical Research, $111(\mathrm{C} 5)$.

Gallagher E.L., Elgar S., and Guza R.T. (1998). "Observations of sand bar evolution on a natural beach," Journal of Geophysical Research, 103 (C2), 3203-3215.

Henderson S.M., Allen J.S., and Newberger P.A. (2004). "Nearshore sandbar migration predicted by an eddy-diffusive boundary layer model," Journal of Geophysical Research 109 (C6).

Hoefel, F., and Elgar, S. (2003). "Wave-induced sediment transport and sandbar migration," Science, 299, 1885-1887.

Holman, R. A., Sallenger, J.A.H., Lippmann, T. C., and Haines, J. W. (1993). "The application of video image processing to the study of nearshore processes", Oceanography, 6, 78-85.

Thornton, E. B., Humiston, R. T., and Birkemeier, W. A. (1996). "Bar/trough generation on a natural beach," Journal of Geophysical Research 101 (C5), 12,097-12,110. 